\title{
ENSAIO: CORRELAÇÃO ENTRE O PERFIL DO SONO E O COMPORTAMENTO EM INDIVÍDUOS COM TRANSTORNO ESPECÍFICO DA APRENDIZAGEM
}

DOI: 10.22289/2446-922X.V7N1A9

Josias Barbosa Victor Lagares ${ }^{1}$

\section{RESUMO}

Este ensaio visa trazer para discussão o artigo dos autores (Amanda Maião Franklin, Célia Maria Giacheti, Nathani Cristina da Silva, Leila Maria Guissoni Campos e Luciana Pinato) que por sua vez trazem uma pesquisa aprofundada de um dos mistérios de nossa humanidade, o sono, buscando correlacionar ao transtorno de aprendizagem, apesar de discutirmos no presente ensaio alguns dos métodos, não podemos deixar de salientar o excelente trabalho das pesquisadoras, em um artigo, que como poderão ver, é bem coeso. A ideia que a falta de sono atrapalha na aprendizagem não é algo novo, porém é muito bem abordado pelas pesquisadoras, que por meio de pesquisa de campo tentaram correlacionar com o Transtorno especifico de aprendizagem.

Palavras-chave: Sono; Aprendizagem; Distúrbio; Transtorno.

\section{ESSAY: CORRELATION BETWEEN SLEEPING PROFILE AND BEHAVIOR IN INDIVIDUALS WITH SPECIFIC LEARNING DISORDER}

\begin{abstract}
This essay aims to bring to discussion the article of the authors (Amanda Maião Franklin, Célia Maria Giacheti, Nathani Cristina da Silva, Leila Maria Guissoni Campos and Luciana Pinato) who in turn bring an in-depth research into one of the mysteries of our humanity, sleep, seeking to correlate to the learning disorder, although we discuss in the present essay some of the methods, we cannot fail to point out the excellent work of the researchers, in an article, which, as you can see, is very cohesive. The idea that lack of sleep disrupts learning is not something new, but it is very well addressed by the researchers, who through field research have tried to correlate with the Specific Learning Disorder.
\end{abstract}

Keywords: Sleep; Learning; Disturb; Disorder.

${ }^{1}$ Endereço eletrônico de contato: josias.23325@alunofpm.com.br

Recebido em 09/11/2020. Aprovado pelo conselho editorial para publicação em 11/02/2021. 


\section{ENSAYO: CORRELACIÓN ENTRE PERFIL DE DORMIR Y COMPORTAMIENTO EN PERSONAS CON TRASTORNO ESPECÍFICO DEL APRENDIZAJE}

\section{RESUMEN}

Este ensayo tiene como objetivo traer a discusión el artículo de las autoras (Amanda Maião Franklin, Célia Maria Giacheti, Nathani Cristina da Silva, Leila Maria Guissoni Campos y Luciana Pinato) quienes a su vez traen una investigación en profundidad sobre uno de los misterios de nuestra humanidad, sueño, buscando correlacionarlo con el trastorno del aprendizaje, aunque discutimos en el presente ensayo algunos de los métodos, no podemos dejar de señalar el excelente trabajo de los investigadores, en un artículo que, como se puede ver, es cohesivo. La idea de que la falta de sueño interrumpe el aprendizaje no es nueva, pero está muy bien abordada por los investigadores, que a través de la investigación de campo han intentado correlacionar con el Trastorno Específico del Aprendizaje.

Palabras clave: Dormir; Aprendiendo; Molestar; Trastorno.

\section{ENSAIO}

O artigo em questão visa correlacionar o sono com o comportamento de indivíduos com transtorno especifico de aprendizagem, para isso foram usados cinquenta e oito indivíduos sendo de ambos os sexos, na faixa etária de oito a treze anos, trazendo como método, questionários de hábitos de sono, escala de distúrbios de sono e diário de sono, para analisar o comportamento foi utilizado o Child Behavior Checklist (CBCL), que por sua vez e um formulário amplamente usado para identificar comportamentos problemáticos em crianças.

Usa-se na pesquisa crianças com (TEAp) em comparação a crianças sem o transtorno, para poderem diferencia-las e dessa forma buscar o ponto em comum entre crianças com distúrbios de sono e crianças com (TEAp), um método simplista porem bem usado pelas pesquisadoras, tendo em vista o número de cobaias, que foi usado pode se dizer que os resultados são no mínimo intrigantes, como poderemos ver ao decorrer desse ensaio.

É de conhecimento de todos que a aprendizagem e algo bem complexo, existindo vários fatores determinantes, tal quais, culturais, biológicos, psíquicos, sociais entre outros, levando em conta isso o artigo se desenvolve em um desses fatores de dificuldade, talvez o mais importante deles, o sono.

O sono por si é algo bem complexo, pois pouco se sabe, e esse pouco é amplamente discutido com diferentes teses as vezes para o mesmo assunto, exemplo disso o sonho, que e amplamente teorizado indo desde profecias a recados do inconsciente, por tempos se acreditava em recado de deuses, hoje apesar do avanço inimaginável da ciência não há uma teoria universal que se pode levar como verdade absoluta. 
Partindo para a ideia principal do artigo, o transtorno especifico de aprendizagem que se caracteriza por alterações persistentes e prejudicais nas habilidades básicas academias como, leitura, escrita, matemática. Apesar das pesquisadoras buscarem a correlação com o distúrbio do sono, esse transtorno pode ser causado por inúmeros motivos, doenças cerebrais, comprometimento visual ou auditivo, mudanças escolares ou até mesmo a falta de oportunidade pela criança.

Após essa definição seguimos para a tese das pesquisadoras, como o sono poderia interferir e ser causa do transtornos de aprendizagem, passando por alunos do ensino fundamental as pesquisadoras passa-os primeiramente por um processo de diagnostico fonoaudiológico, no questionário foram acrescentados informações sobre comportamento da hora de dormir, tipo de escola e rotina de estudo, resultando nas trinta e cinco perguntas, divididas em dezenove sobre rotinas, quatro sobre a saúde, cinco sobre atividades diárias e seis quanto o ambiente de sono, 0 diário do sono era-se observado pelos pais e responsáveis durante o período de cinco dias, horários do sono e do despertar, tempo passado na cama e o tempo dormindo, estado de sono ao longo do dia, dispersores noturnos e a forma que o indivíduo desperta, todas essas informações para se ter uma escala do distúrbio do sono, usando como base a versão brasileira da (EDSC).

Ao final do estudo as pesquisadoras, compararam o grupo com (TEAp) com o grupo controle, nesse ponto o artigo se faz bem informativo, trazendo resultados que realmente compactuam a teoria principal, pacientes com (TEAp) tendem a ter distúrbios de sono, sendo eles $65 \%$ favoráveis a tese.

Conclui- se então que segundo o estudo a grande maioria dos pacientes testados tem sim os distúrbios de sono de diferentes escalas, apesar disso, cabe salientar que, essa correlação precisa de estudos mais aprofundados, como bases comportamentais mais densas, número maior de cobaias. Apesar disso o estudo em questão e bem promissor, tendo em vista que o sono precisa ser mais amplamente teorizado e trazendo essa iniciativa as pesquisadoras brasileiras abrem um leque de discursões mais aprofundadas sobre o quão importante o sono regular pode ser, cada vez mais temos estudos e resultados intrigantes sobre o sono e seus nuances, esses resultados podem ser o começo de uma grande comprovação no futuro, excelente iniciativa e pesquisa das brasileiras.

\section{REFERÊNCIAS}

Franklin et al.. (2018). Correlação entre o perfil do sono e o comportamento em indivíduos com transtorno específico da aprendizagem. CoDAS [online], 30(3), 1-8. https://doi.org/10.1590/2317-1782/20182017104 